\title{
Life cycle approach to sustainability assessment: a case study of remanufactured alternators
}

\author{
Erwin M. Schau*, Marzia Traverso and Matthias Finkbeiner
}

\begin{abstract}
Sustainability is an international issue with increasing concern and becomes a crucial driver for the industry in international competition. Sustainability encompasses the three dimensions: environment, society and economy. This paper presents the results from a sustainability assessment of a product. To prevent burden shifting, the whole life cycle of the products is necessary to be taken into account. For the environmental dimension, life cycle assessment (LCA) has been practiced for nearly 40 years and is the only one standardised by the International Organization for Standardization (ISO) (14040 and 14044). Life cycle approaches for the social and economic dimensions are currently under development. Life cycle sustainability assessment (LCSA) is a complementary implementation of the three techniques: LCA (environmental), life cycle costing (LCC - economic) and social LCA (SLCA - social). This contribution applies the state-of-the-art LCSA on remanufacturing of alternators aiming at supporting managers and product developers in their decision-making to design product and plant. The alternator is the electricity generator in the automobile vehicle which produces the needed electricity. LCA and LCC are used to assess three different alternator design scenarios (namely conventional, lightweight and ultra-lightweight). The LCA and LCC results show that the conventional alternator is the most promising one. LCSA of three different locations (Germany, India and Sierra Leone) for setting the remanufacturing mini-factory, a worldwide applicable container, are investigated on all three different sustainability dimensions: LCA, LCC and SLCA. The location choice is determined by the SLCA and the design alternatives by the LCA and LCC. The case study results show that remanufacturing potentially causes about $12 \%$ of the emissions and costs compared to producing new parts. The conventional alternator with housing of iron cast performs better in LCA and LCC than the lightweight alternatives with aluminium housing. The optimal location of remanufacturing is dependent on where the used alternators are sourced and where the remanufactured alternators are going to be used. Important measures to improve the sustainability of the remanufacturing process in life cycle perspective are to confirm if the energy efficiency of the remanufactured part is better than the new part, as the use phase dominates from an environmental and economical point of view. The SLCA should be developed further, focusing on the suitable indicators and conducting further case studies including the whole life cycle.
\end{abstract}

Keywords: Life cycle sustainability assessment, Life cycle assessment, Life cycle costing, Social LCA, Remanufacturing, Alternator, Automotive parts, Germany, India, Sierra Leone

\footnotetext{
* Correspondence: erwin.m.schau@gmail.com

Department of Environmental Technology, Chair of Sustainable Engineering,

Technische Universitaet Berlin, Office Z1, Strasse des 17. Juni 135, Berlin

D-10623, Germany
} 


\section{Background}

The alternator is the automotive part with the highest remanufacturing rate [1]. The function of the alternator is to deliver electrical energy to charge the battery and to the on board equipments like light [2].

Remanufacturing can play an important role as a way to close the material cycles and thereby contribute to less material and energy use [1,3-7], which are the important steps to realise a sustainable development.

However, in a life-cycle perspective, not only the production or remanufacturing phase but also the use stage is needed to be taken into account. In the use stage of engines and generators, energy use, associated emissions and costs are of high concern [8]. Up to now, few studies have looked at the whole life cycle of automotive parts that requires energy in the use phase including remanufacturing of the used parts [9].

Sustainability encompasses not only the environmental dimension, but also social and economic ones, as it is defined by the Brundtland Commission [10]. Consequently, a methodology to measure sustainability is getting extremely important. The measurement of the environmental dimension of sustainability is the most mature method of the three.

LCA is a standardised method [11,12] widely used to investigate the potential environmental impacts of products and services through the whole life cycle from cradle to grave $[13,14]$. The life cycle approach helps to avoid shifting of burden from one phase to another.

Life cycle costing (LCC) is proposed for the assessment of the economic dimension of sustainability. LCCs have been used since the 1930s [15]; however, it is a relatively new tool within sustainability assessment. The Society of Environmental Toxicology and Chemistry (SETAC) working group on LCC [16] classifies three types of LCC conventional, environmental and societal LCC and considers the method of environmental LCC [16] currently as the most suitable for combining with LCA $[15,17,18]$.

Social life cycle assessment (SLCA) is the life cycle tool to assess the potential social and socio-economic impacts of the products and their consumption throughout their life cycles [19].

To combine LCA, environmental life cycle costing (LCC) $[16,20]$ and SLCA [19], a methodology called Life Cycle Sustainability Assessment (LCSA) [21] has been suggested and can be formally expressed in the symbolic equation [22-25]:

$$
\mathrm{LCSA}=\mathrm{LCA}+\mathrm{LCC}+\mathrm{SLCA},
$$

where

1. LCSA = Life cycle sustainability assessment,

2. $\mathrm{LCA}=$ Environmental life cycle assessment,

3. $\mathrm{LCC}=$ Environmental life cycle costing and

4. SLCA $=$ Social life cycle assessment

Based on the well-known depiction of sustainability, where the three dimensions of environment, economy and society intersect, as depicted in Figure 1a, the LCSA can be illustrated synchronously as previously described (Figure 1b).

Similar to the LCA method, environmental LCC and SLCA are life cycle approaches which have been proven useful to prevent shifting of burden from one process to another in the product life cycle [23]. Despite the long history of conventional life cycle costing, the environmental LCC is a relatively new method in a sustainability context [20]. SLCA is still in its infancy, where one of the current focuses is developing the indicators to be used [22].

This paper presents the results from a multidisciplinary research project applying LCSA on different scenarios for remanufactured alternators - three different countries and three different alternator designs are investigated - and thereby lead contribution to the development of the LCSA methodology. The whole life cycle is considered (for the LCA and the environmental LCC), but the main focus in this paper is on the remanufacturing process. Thereby, the measurements to improve the sustainability of the $\mathbf{a}$

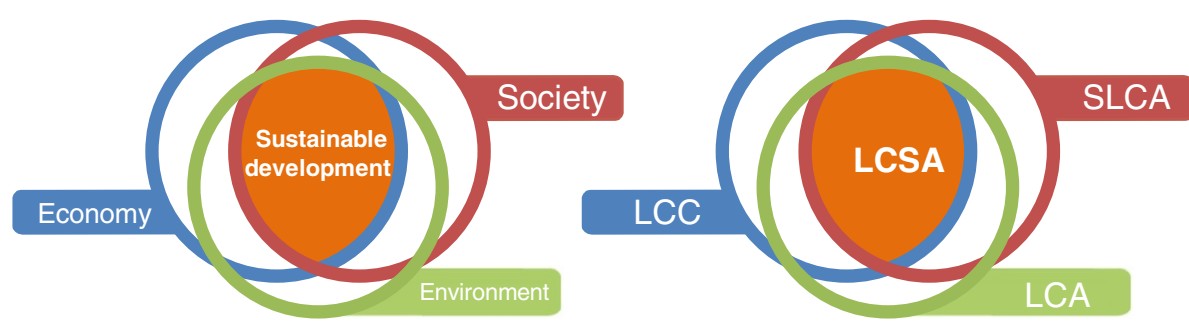

Figure 1 Dimensions of sustainability and life cycle sustainability assessment. (a) The three dimensions of sustainability based on [26]. (b) Life cycle sustainability assessment (LCSA) consists of environmental life cycle assessment (LCA), environmental life cycle costing (LCC) and social LCA (SLCA). 
remanufacturing have been identified. Where data permits, the comparison between the new alternators and the remanufactured ones is performed.

\section{Methods}

The life cycle assessment of the three dimensions: environment, economy and society should ideally use the same system boundary and the same reference unit [27] - called the functional unit (FU) - a unit which all the results are related to and which quantify the performance (valuable main output) of the system [11]. The life cycle inventory for a LCA includes all exchanges or flows e.g., materials and energy between the technosphere (economy) and the nature (environment) crossing the system boundary $[13,28]$. However, due to the different flows to consider, method maturity and data access of the LCA, LCC and SLCA techniques, the use of the same life cycle inventory is difficult to realise.

LCA is a well-known tool standardised in the ISO14040/ 14044 and used to investigate the potential environmental impacts of products and services. LCA is divided into four phases: goal and scope definition, life cycle inventory analysis, life cycle impact assessment and interpretation in an iterative process $[11,12]$.

Hunkeler et al. [16] defined environmental LCC as 'An assessment of all costs associated with the life cycle of a product that are directly covered by any one or more of the actors in the product life cycle (e.g., supplier, manufacturer, user or consumer, or EoL actor) with complementary inclusion of externalities that are anticipated to be internalized in the decision-relevant future. (...) Environmental LCC has to be accompanied by a life cycle assessment and is a consistent pillar of sustainability.'
This definition is our starting point for the LCC. Since the flows investigated in LCC is of monetary art, all costs have their counterpart in an income. Therefore, the system boundaries and the stakeholder perspective taken, e.g. that of the user, are of importance for the results of the LCC [8].

SLCA assesses the social impacts on workers, the local communities, the consumers, the society and all other value chain actors affected by the production and consumption of products under consideration [19]. According to the guideline of social LCA [19] (published by United Nations Environment Programme UNEP/SETAC Life Cycle Initiative), a generic SLCA can be implemented as a first step to identify the social hotspots.

The life cycle of the alternator is modelled as shown in Figure 2 and used for the LCA. Starting with the left part of the figure, the production phase consists of raw material extraction, material processing and manufacturing. In the use phase, the alternator generates the necessary electricity for the automobile during its $200,000 \mathrm{~km}$ or about 13 years lifetime. Subsequently, the alternator is remanufactured in a mini-factory and placed in a container for worldwide use. Arrows indicates transport; however, at this stage, a detailed logistic system is not in place, such that it is assumed that the transport is the same for all design alternatives.

The remanufactured alternator can be used again as an electrical generator in the vehicle. The use phase is modelled once for Germany only. The remanufactured alternators are applied in the used vehicle already driven some distance. Therefore, the 200,000 km FU may be restricted by the (rest) of the vehicle - as this may be scrapped before driving at $200,000 \mathrm{~km}$ with the

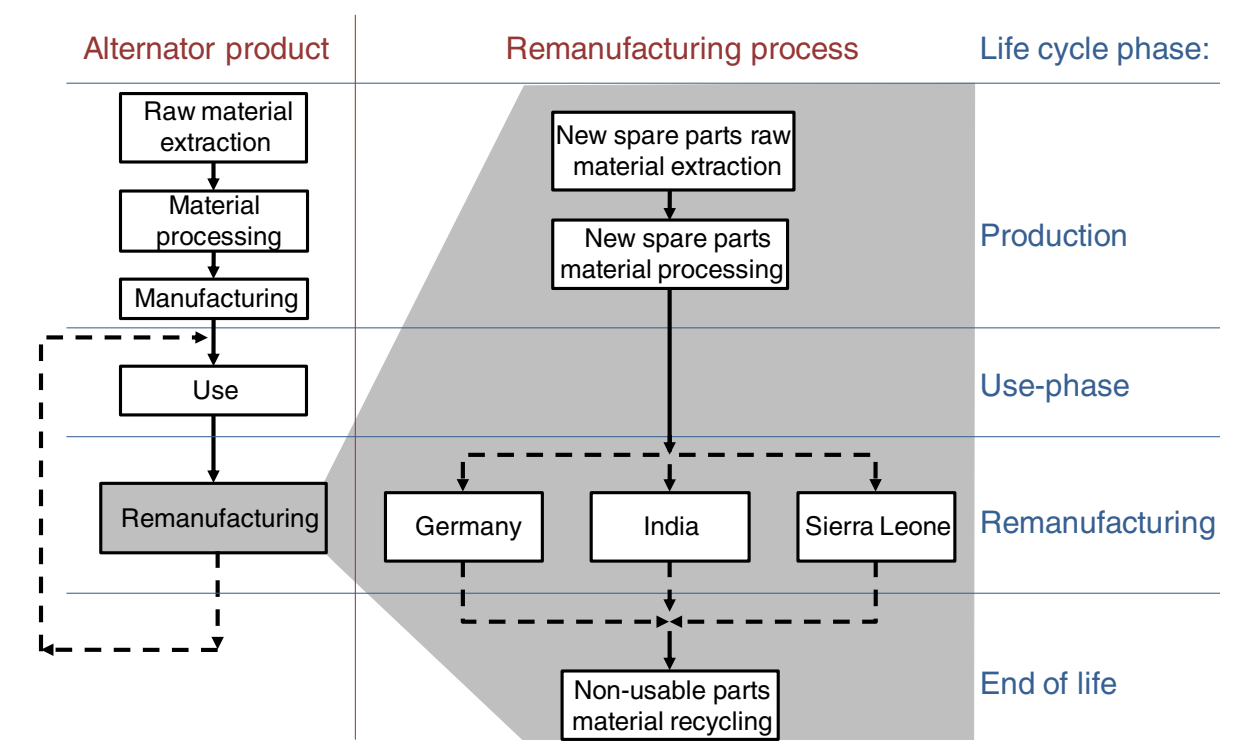

Figure 2 System under study. 
remanufactured alternator. However, to facilitate the comparison of the new alternators to the remanufactured alternator, the FU of $200,000 \mathrm{~km}$ is used also on the remanufactured alternator.

The middle part of Figure 2 focuses on the remanufacturing process. In addition to the used alternator, the remanufacturing process needs some new alternator spare parts which are sourced globally. Similar to the new alternator production, raw material extraction and material processing are needed for the new spare parts. The remanufacturing scenario will take place in the container mini-factory equipped with all necessary tools and model to be set in Germany, India or Sierra Leone. The final stage, which is the end of life, is modelled as a part of the remanufacturing phase and includes also those fractions of the used alternators that cannot be used anymore $(10 \%$ to $100 \%$ cf. Table 1$)$. The right hand side of Figure 2 names the different life cycle phases.

The perspectives of the remanufacturer and the user (of the remanufactured alternator) are presented for the environmental LCC. Due to the case study's prospective nature and connected limited data access, only the three different potential remanufacturing sites in Germany, India and Sierra Leone are investigated for the SLCA.

Data for the LCA is mainly taken from and modelled in the $\mathrm{GaBi} 4.0$ database [31], and the characterization factors used was CML2001 [13] (with update in [32]); whereas the environmental LCC is estimated using literature and invited quotations [8]. The data for the SLCA are from the social hotspot database [33,34] and other international database available online in addition to scientific literature.
Three different design alternatives are investigated by LCA and environmental LCC. The design alternative 1 is a conventional alternator (weight; $6.069 \mathrm{~kg}$ ) with belt fitting, fan and steel bearings and cast iron housing. Design alternative 2 is a lightweight alternator $(4.378 \mathrm{~kg}$ ) with a plastic fan and aluminium housing. Design alternative 3 is an ultra-lightweight alternator $(3.952 \mathrm{~kg}$ ), where also the belt fitting and bearings are replaced by lightweight parts (aluminium and plastic respectively). Table 1 shows the material, weight, and replacement probability (the likelihood of a part being replaced within the alternator by the remanufacturer) of the different parts of the alternator for each design alternatives. The new materials, weight and replacement probabilities (in alternatives 2 and 3) are best estimates made by the designers. These are highlighted in italics in Table 1.

\section{Results}

First in this section, the environmental dimension is presented; second, the economic dimension; third, the social dimension. The results of the LCSA are summarised at the end of this section by applying the Life Cycle Sustainability Dashboard [35].

\section{Environmental dimension: LCA of the remanufactured alternator}

In this section, the LCA results for all steps of the product life cycle: production, use and remanufacturing are presented. Afterward, the comparison of the three different design alternatives and the different localization options are expressed.

Table 1 Alternator parts, materials, weights and replacement probabilities [29] for each of the design alternatives 1-3

\begin{tabular}{|c|c|c|c|c|c|c|c|c|c|}
\hline \multirow[b]{3}{*}{ Part } & \multicolumn{3}{|c|}{ Design alternative 1} & \multicolumn{3}{|c|}{ Design alternative 2} & \multicolumn{3}{|c|}{ Design alternative 3} \\
\hline & \multicolumn{3}{|c|}{ Conventional generator [29] } & \multicolumn{3}{|c|}{ Lightweight generator $[29,30]$} & \multicolumn{3}{|c|}{ Ultra-lightweight generator $[29,30]$} \\
\hline & Material & Weight (kg) & $\begin{array}{l}\text { Replacement } \\
\text { probability (\%) }\end{array}$ & Material & Weight (kg) & $\begin{array}{l}\text { Replacement } \\
\text { probability (\%) }\end{array}$ & Material & Weight (kg) & $\begin{array}{l}\text { Replacement } \\
\text { probability (\%) }\end{array}$ \\
\hline Stator & Steel & 0.773 & 20 & Steel & 0.773 & 20 & Steel & 0.773 & 20 \\
\hline Rotor coil & Copper & 0.550 & 22 & Copper & 0.550 & 22 & Copper & 0.550 & 22 \\
\hline Rotor & Iron cast & 1.094 & 19 & Iron cast & 1.094 & 19 & Iron cast & 1.094 & 19 \\
\hline Drive shaft & Steel & 0.262 & 10 & Steel & 0.262 & 10 & Steel & 0.262 & 10 \\
\hline Belt fitting & Steel & 0.519 & 10 & Steel & 0.519 & 10 & Aluminium & 0.180 & 75 \\
\hline Fan & Steel & 0.138 & 10 & Plastic/PP & 0.016 & 100 & Plastic/PP & 0.016 & 100 \\
\hline Spacer & Aluminium & 0.003 & 50 & Aluminium & 0.003 & 50 & Aluminium & 0.003 & 50 \\
\hline Bearings & Rolled steel & 0.099 & 50 & Rolled steel & 0.099 & 50 & Plastic/PP & 0.011 & 100 \\
\hline Slip ring $N$ & Copper & 0.033 & 100 & Copper & 0.033 & 100 & Copper & 0.033 & 100 \\
\hline Slip ring $S$ & Copper & 0.071 & 100 & Copper & 0.071 & 100 & Copper & 0.071 & 100 \\
\hline Housing & Iron cast & 2.527 & 15 & Aluminium & 0.958 & 40 & Aluminium & 0.958 & 40 \\
\hline Sum & & 6.069 & - & - & 4.378 & - & - & 3.952 & - \\
\hline
\end{tabular}


The life cycle impact assessment results are pictured in Figure 3, which show that the use phase plays a dominating role. The exception is that in abiotic depletion potential (ADP), marine aquatic ecotoxicity potential and radioactive radiation (RAD) where the production phase is dominating. Figure 3 also indicates that the remanufacturing causes about $1 / 8(12 \%)$ of the emissions compared to the production of the new part. The ADP indicator is a measurement of the resources and energy needed and is displayed in two components: ADP elements and ADP fossil fuels. The ADP elements are dominated by the production phase (71\%), followed by the remanufacturing phase $(24 \%)$. The use phase $(5.5 \%)$ is relatively unimportant in the ADP elements. However, in the ADP fossil fuels, the use phase is totally dominating the overall life cycle result (99\%) as expected as the alternator needs energy (taken from the internal combustion motor running on fossil fuel) to work. The ADP elements, which describe the use of mineral resources (e.g. copper) excluding fuels, can be explained further as the results are somehow counter-intuitive. First, the low share of the ADP elements in the use phase is explained by that the consumption during this phase is mainly fuel from abiotic resources (Petrol) and thereby part of the ADP fossil fuel. Second, the remanufacturing requires roughly $1 / 3$ of the ADP element compared to the production (including upstream processes). This relatively high share (compared to the roughly $1 / 8$ of the emissions) can be explained by the copper needed in the remanufacturing to replace the rotor coil (in $22 \%$ of the cases) and the slip rings each time (in $100 \%$ of the cases). The production of pig iron and primary aluminium contributes to the radioactive radiation. The primary aluminium production is the main cause of marine aquatic ecotoxicity potential, mainly lead, by the emission of hydrogen fluoride to the air [31]. In the use phase, ADP fossil fuels and the global warming potential are dominated by the direct combustion of fuel. For the other impact categories, the use phase dominated due to the upstream processes of the fuel production.

Figure 4 shows the LCA results for a complete life cycle (from raw material extraction to use and finally remanufacturing) for design alternative 2 (lightweight) and design alternative 3 (ultra-lightweight) compared to design alternative 1 (conventional alternator). The remanufacturing site shown in Figure 4 is Germany. The conventional alternator has the best performance for all impact categories investigated. This is caused by (a) the conventional parts (e.g., made of cast iron) which have a low replacement probability in contrast to the lightweight parts (e.g., aluminium and plastics) and (b) the upstream environmental impacts of the conventional materials is smaller compared to the lightweight materials. If we observe the remanufacturing process ( $c f$. Figure 2 ), these effects are very clear, as Figure 5 discloses.

Figure 5 represents the LCA results for design alternatives 2 (lightweight) and 3 (ultra-lightweight) relative to design alternative 1 (conventional) of remanufactured alternators. Only the remanufacturing process is showed for only one site (Germany). The range of the difference between the lightweight alternatives 2 and 3 and the conventional alternator is from two to eight times, except in the ADP elements where the differences are much smaller $(11.3 \%$ and $2.5 \%$ in favour of the conventional alternator).

For the abiotic depletion impact category, the differences between the three design alternatives are small compared to the other impact categories investigated

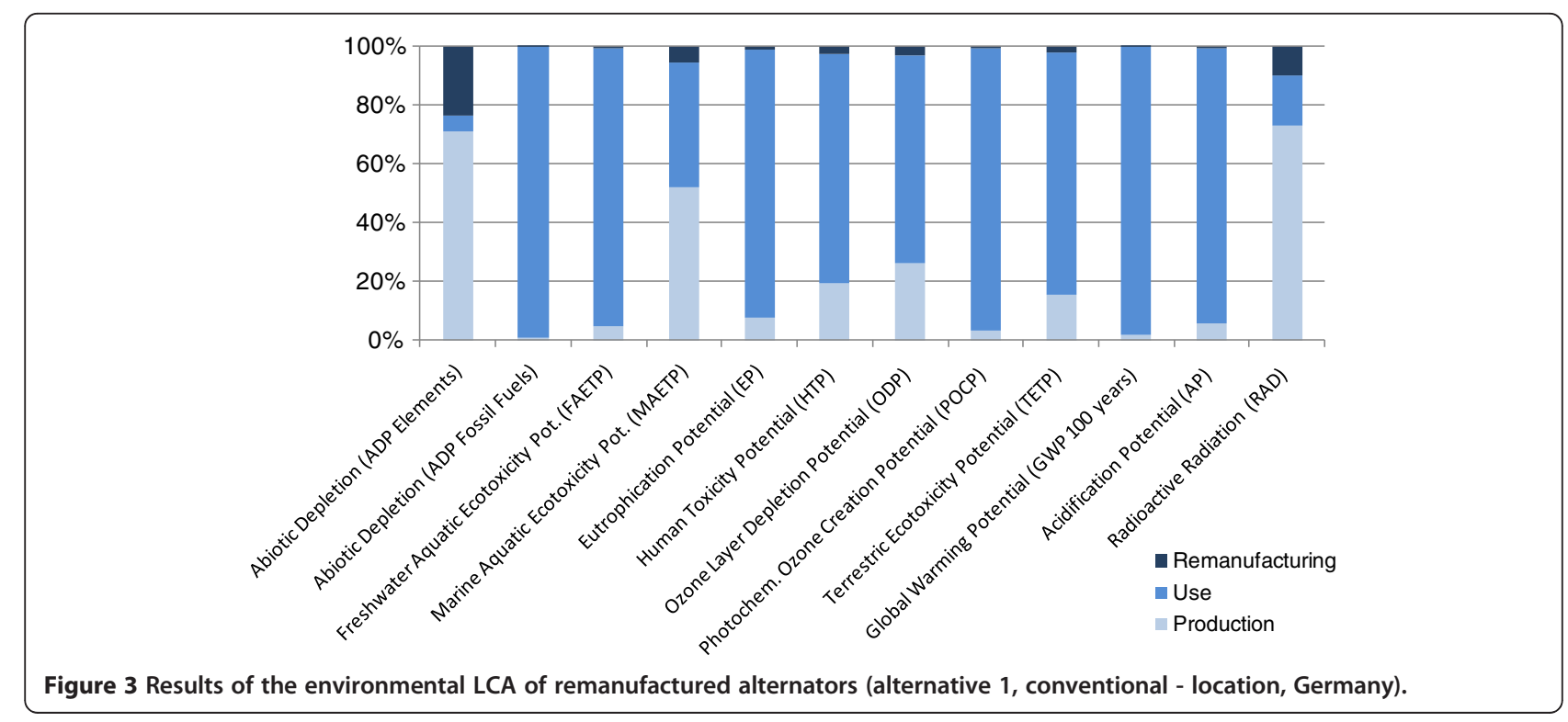




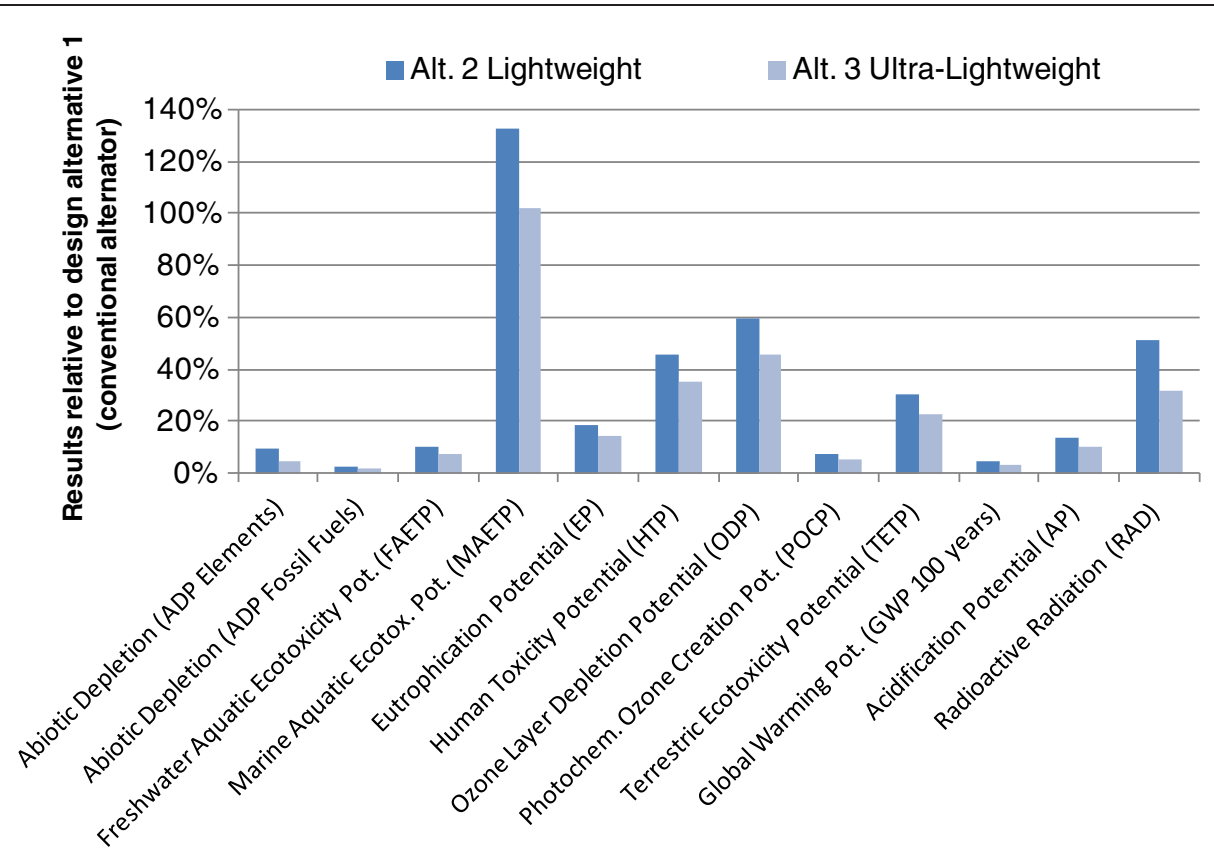

Figure 4 Results from the environmental LCA of remanufactured alternators. Complete life cycle (Germany only), design alternative 2 (lightweight) and 3 (ultra-lightweight) compared to design alternative 1 (conventional alternator).

(factors 2-8 cf. Figure 5). This can be explained by the ADP elements that roughly reflect the material use in the different design alternatives. This effect is scaled up as the fossil fuels (ADP fossil fuels) and emissions in the upstream processes needed are taken into account.

\section{Comparison of different localization option (alternator remanufacturing)}

Figure 6 shows the LCA results for the alternator 1, the conventional one, for the remanufacturing at the three different localizations investigated. The LCA results for the different localization options do not show very much variation compared to the different alternator designs
( $c f$. preceding sections). New spare parts are assumed to be sourced globally. Their upstream processes contribute the largest portion to the LCA results. The electricity use, which is drawn from the national grid in Germany and India (with their respective grid mix of power sources) and produced locally at the remanufacturer by diesel aggregates in Sierra Leone, explains some of the differences.

\section{Economic dimension: LCC}

In this section, firstly, the economic dimension from the remanufacturer perspective is presented and then the user perspective.

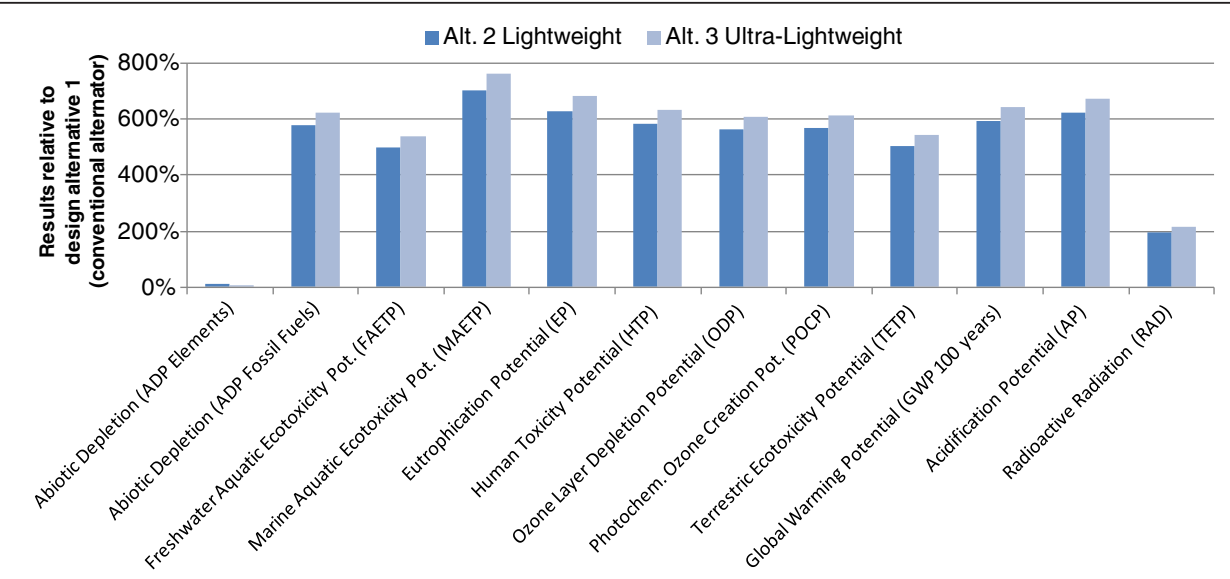

Figure 5 LCA results for the remanufacturing only (in Germany). Design alternatives 2 (lightweight) and 3 (ultra-lightweight) relative to design alternative 1 (conventional). 


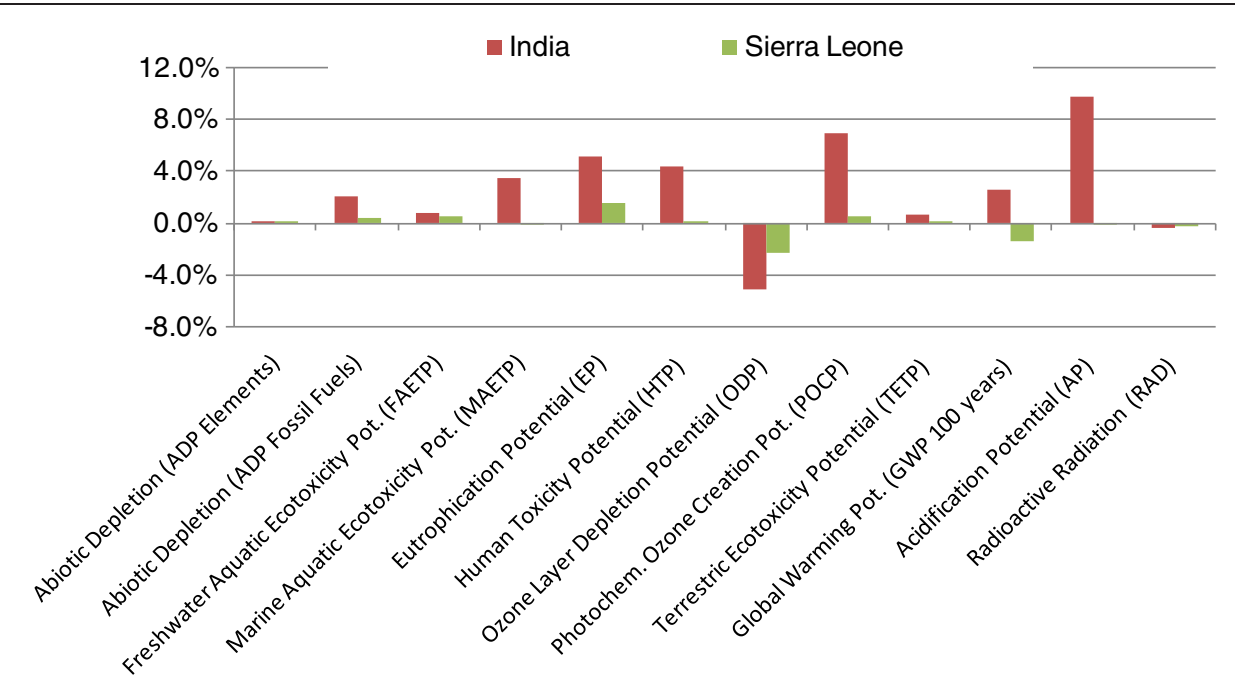

Figure 6 LCA results for different remanufacturing localizations - India and Sierra Leone relative to Germany (alternative 1, conventional-remanufacturing only).

Figure 7 shows the results from the environmental LCC from the remanufacturer perspective. Potential costs for the used alternators and new spare parts are assumed to be the same in India and Sierra Leone as in Germany. Transport cost includes oversea shipping to Germany from the India and Sierra Leone locations.

Cost for warranties is the only cost from the remanufacturer perspective that occurs in the use phase. The costs of (new) spare parts and used alternators acquisition are dominating. The differences between the different alternator design alternatives are significant, where alternator 1 , the conventional one, has the lowest potential costs. The differences between the location choices are, however, mainly decided by the transport cost, and thereby depended on where the remanufactured alternator is used. Labour costs play a minor role in Germany, and are almost negligible in India and Sierra Leone, as the same as the cost of energy for cleaning used parts and cost for warranties. It was surprising that the labour cost was so less important even in Germany, as the remanufacturing industry is normally considered as being labour intensive [36].

Figure 8 displays the LCC results from the user perspective. The fuel use cost for power production is dominating and is the same for all three alternatives. The largest difference between the design alternatives is found in the cost of repair and maintenance, where the lightweight alternatives 2 and 3 are estimated to need some repair and maintenance during their lifetime. The lightweight material used here are less durable than in the conventional design (alternative 1). The corresponding slightly lower weight-induced fuel use cost for the lightweight alternatives 2 and 3 cannot balance out the higher acquisition cost of these designs compared to the conventional one. This can be explained by the higher cost of the new lightweight spare parts for the remanufacturer ( $c f$. Figure 7$)$, which is passed on to the user

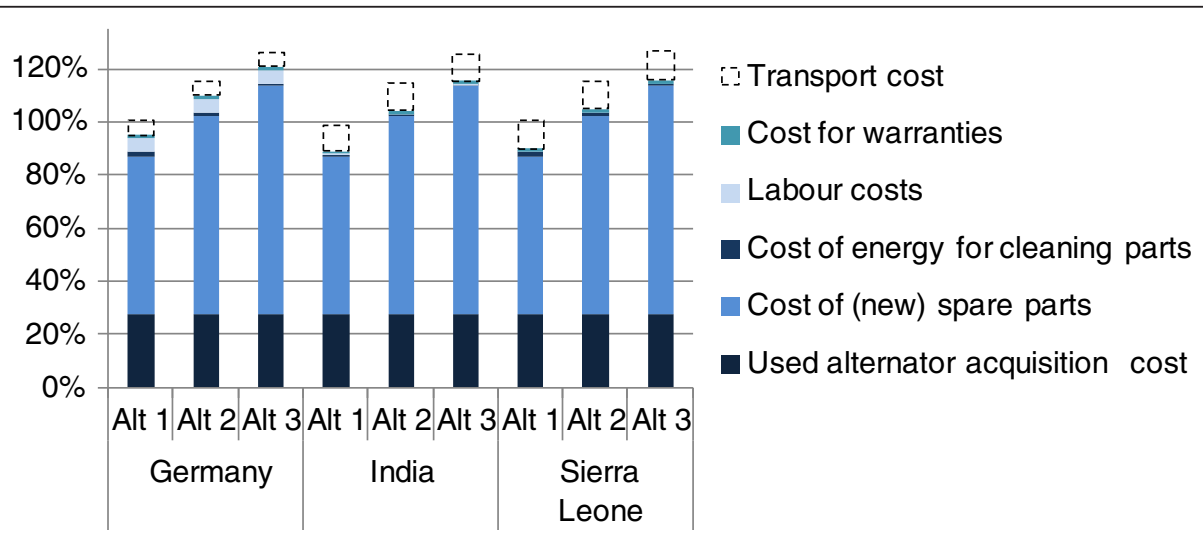

Figure 7 LCC results from the remanufacturer perspective. 


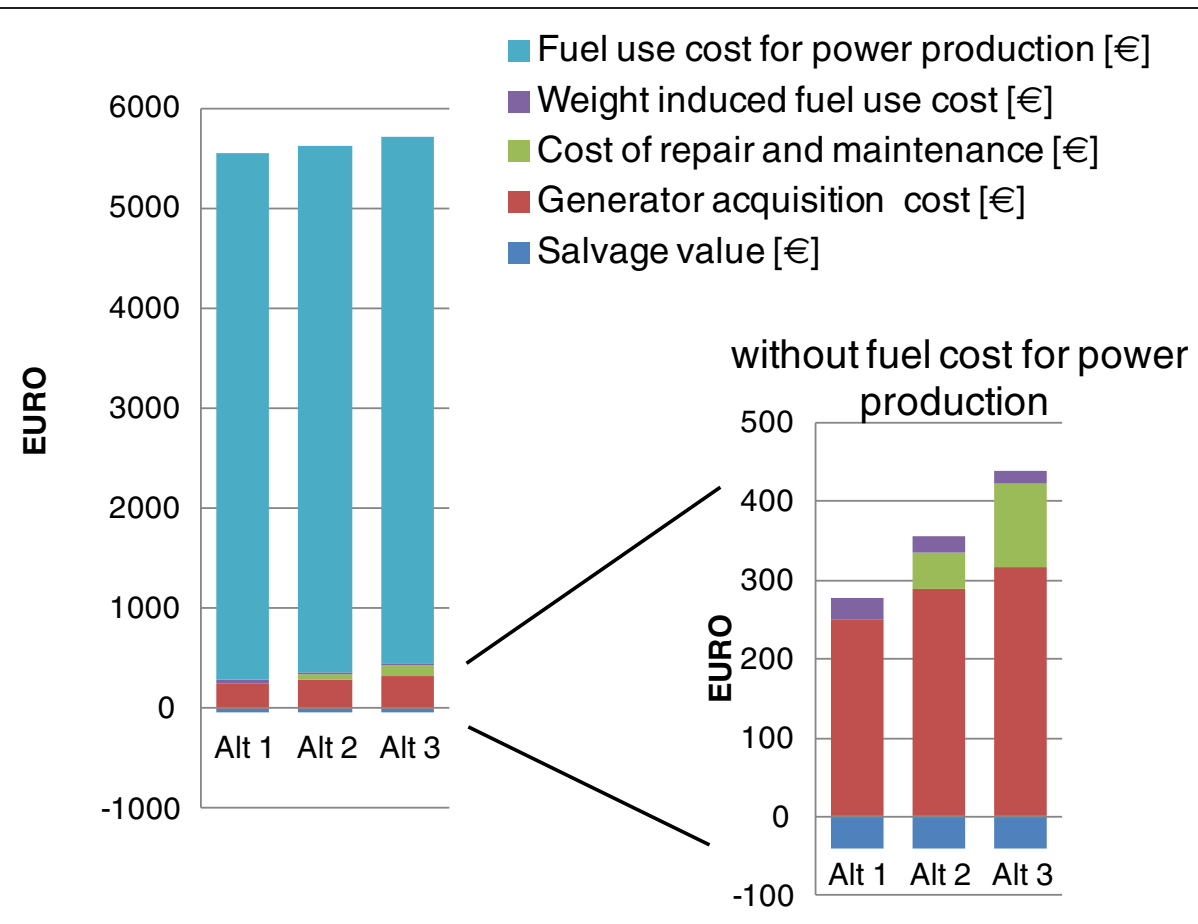

Figure $8 \mathrm{LCC}$ results from the user perspective.

(plus tax and profit margins). The salvage value is depicted below the $x$-axis in Figure 8 as this is an income (negative cost) for the user at the end of the lifetime.

\section{Social dimension: SLCA}

The main social factors of Sierra Leone and India can be identified by using the Social Hotspots database available $[34,37]$. The Social Hotspots database reveals very high risks in Sierra Leone for the following topics [34]:

1. Potential of country not adopting Labour Conventions

2. Percentage of population living on less than US\$2/ day

3. Risk of child labour

4. Overall fragility of legal system

5. Overall fragility of gender equity

6. Risk of not having access to improved sanitation (total, rural and urban) and

7. Risk of not having access to improved drinking water (total).

A better scenario is shown about India, where the social hotspots shows very high risks for topics such as [34]:

1. Potential of country not adopting Labour Conventions
2. Percentage of population living on less than US\$2/ day

3. Potential for high conflict

4. Overall fragility of gender equity and

5. Risk of not having access to improved sanitation (total, rural and urban)

For Germany, the Social Hotspots database does not show very high risks for any of the topics covered [34].

Among these social hotspots, the ones that can be directly affected by a remanufacturing plant are child labour (children aged less than 15 years), salary and gender equity. According to the Social LCA guidelines [38], we should consider the main affected stakeholder group, which in this case is the workers. The Social LCA guidelines report the main impact subcategories of the workers' group, such as salary, child labour, health and safety and freedom of association, just to mention a few subcategories. Data collection on the working conditions should be carried out, and primary data about the previous indicators should be collected from the three remanufacturing mini-factories. Because the three remanufacturing mini-factories are not in place yet and the focus of this work is the assessment of the three scenarios, we mainly identify their potential positive and negative impacts.

Child labour is about 48\% (2005) [39] in Sierra Leone and about $12 \%(2005,2006)$ in India [40]. Child labour 
is not an issue in Germany, which has ratified the ILO 'Minimum Age Convention' [41] that legally prohibits child labour.

In relation to women discrimination, some data are reported in Table 2. The newest data for Sierra Leone existing is from 2001 [42]. To facilitate a better comparison between the countries, 2001 data from Germany and India were also shown in the table. An increase in the values for India can be recognised; for example, the ratio of female to male secondary enrolment increased to $88 \%$ in 2007 . The values for Germany are stable on a high level [42].

The population living under US $\$ 2 /$ day is about $76.1 \%$ in Sierra Leone [43] and 75.6\% in India [43] (also in this case, it is not an issue for Germany). Therefore, it is important to consider the worker salary or in this case, the minimum wage. In Germany, there is no general statutory law on the minimum wage. However, labour organisations are relatively strong in the German remanufacturing sector and wages are according to the general tariff negotiated between the employer and employee organisations. In the LCC estimations, $24.50 € / \mathrm{h}$ as cost for employers during the remanufacturing has been used [44], but this number includes all social costs which are relatively high in Germany.

In India, wages in the remanufacturing sector have been estimated based on some available databases $[45,46]$ to be about $1.54 € / \mathrm{h}$ in 2006 . However, the trend in Indian wages shows a relatively rapid growing trend [45]. The national minimum wage floor has been risen from 80 INR (Indian rupees, about $1.42 €$ ) in 2007 to 100 INR (about $1.48 €$ ) in 2009, but the actual minimum wages are set regionally [47]. For example, in the automobile repair section of the Maharashtra region, the total minimum wage for a semi-skilled worker was 5,813.60 INR per month [48] or about $2.30 € / \mathrm{h}$ (March 2011).

Sierra Leone is one of the poorest countries in the world, and the wages are generally low. There is a statutory minimum wage in Sierra Leone of 25,000 leones per month (less than 1 Euro), too low to secure a decent living [49]. In the remanufacturing sector, the average wage is about 4 million Le [50] (about 1,000 Euro) per year and equals an hourly rate of about $0.50 € / \mathrm{h}$. This wage includes $13.65 \%$ social contribution [50]. Table 3 summarises the social factors for Germany, India and Sierra Leone.
An implementation of Life Cycle Sustainability Dashboard To summarise and present the previous results from the LCSA in a consistent way to the decision makers, we use the Life Cycle Sustainability Dashboard (LCSD). The LCSD is a spreadsheet tool and a specific application of the Dashboard of Sustainability and is used to compare different products or scenarios [22]. The LCSD uses a colour scale ranging from red (bad) via yellow (intermediate) to green (good) to present the comparison of the results of the three dimensions of sustainability [51]. Figure 9 shows a screenshot of the sustainability dashboard for the three different alternator designs remanufactured in Germany.

As indicated from Figure 9, alternator 1 is the best design alternative, showing the best performance in the LCA and also showed good results for the LCC. The SLCA in Figure 9 for all alternatives are the same, as we only assess the social dimension for the different location choices, but not for different design alternatives.

\section{Discussion}

The results are dependent on the underlying assumptions and data. In this study the replacement probabilities for the different parts of the alternator are of major importance. These are collected from the different remanufacturer in the greater Berlin region (Berlin-Brandenburg) by another member of the larger research project in which this paper is a part. As the underlying replacement probabilities data are not collected by the authors of this paper, it has not been possible to investigate the range of this data. Furthermore, to which degree the data from the Berlin region represent Germany without having the data from the rest of Germany is difficult to judge. But as remanufactured alternators and cores are frequently shipped throughout Germany, the replacement probabilities used are assumed not to differ very much from the German average. This may also be the case where used alternators from Germany are shipped to India and Sierra Leone for remanufacturing there. However, for the Indian and Sierra Leone location, the replacement probability may be very well different if the used cores are locally or globally sourced. It has not been part of the scope of this research to investigate the replacement probabilities for alternator parts in these countries. Therefore, the results presented on the different design alternatives in this study are focused on the German location only. Furthermore, the

Table 2 Social indicators on the gender equity [42]

\begin{tabular}{llll}
\hline Indicator name (data from year 2001) (\%) & Germany & India & Sierra Leone \\
\hline Ratio of female to male primary enrolment & 99.4 & 85.1 & 68.1 \\
Ratio of girls to boys in primary and secondary education & 98.8 & 79.6 & 68 \\
Ratio of female to male secondary enrolment & 98.5 & 71.7 & 68 \\
Proportion of seats held by women in national parliaments & 31 & 9 & 9 \\
\hline
\end{tabular}


Table 3 Social factors relevant for the remanufacturing plant

\begin{tabular}{llll}
\hline & Germany & India & Sierra Leone \\
\hline Ratio of population living under US\$2/day $(\%)$ & na & 75.6 & 76.1 \\
Estimated hourly rate in the remanufacture industry $(€ / h)$ & 24.50 & 1.54 & 0.50 \\
Minimum wage $(€ /$ month) & na & 92 & $<1$ \\
\hline
\end{tabular}

na, not applicable.

replacement probability for the lightweight parts is an expert estimate from the design team involved in the research reported here. As these are new designs, actual statistics from the remanufacturing of such parts is very limited. Further research should focus on the better numbers for the replacement probabilities, and especially for the lightweight parts, as this will increase the reliability of the results.

The main environmental (and economic) impacts are from the use phase, when the alternator delivers electricity for the battery and on board electronic devices. This result heavily relies upon the efficiency of the motor to transform chemical energy in the diesel/petrol to rotational energy and the alternator itself to transform rotation energy from the motor to electric energy. While the motor efficiency is well-documented, the average efficiency is heavily dependent on different factors like speed, load and operating conditions [52]. To find reliable data on the alternator efficiency was, however, not that easy. The assumed average used in this study is 55\% alternator efficiency based on [52]. This is the same number and source used in a master thesis of modelling remanufactured automotive alternators - however, it was not used in cars but in small wind turbines [53]. Bosch, a large manufacturer (and remanufacturer) of alternators, publishes an edition of know-how for automobiles. In this book, Meyer [2] lists a maximum alternator efficiency of $65 \%$; he noted, however, that the mean efficiency is between $55 \%$ and $60 \%$. A minimum efficiency is not given [2]. In other older literature, the alternator efficiency is reported to be between $40 \%$ and $64 \%$ [54] such that our choice of $55 \%$ alternator efficiency seems reasonable. Note also in this respect that our basic assumption is that the remanufactured alternators are as good as new ones (which is close to the definition of remanufacturing - see e.g. [55]) such that the energy transformation efficiency is the same.

A finding in this study is that the much favoured lightweight strategy is not necessarily fruitful when the life cycle of the automotive part like the alternator is taken into account. In our LCA and LCC studies of three different designs for remanufactured alternators, the conventional (heavy) alternator scores are better than both the lightweight (alternative 2) and the ultra lightweight ones (alternative 3). The use phase is dominating the life cycle environmental impact of the remanufactured alternator. This is not surprising for a product requiring energy in the use phase. When comparing the different

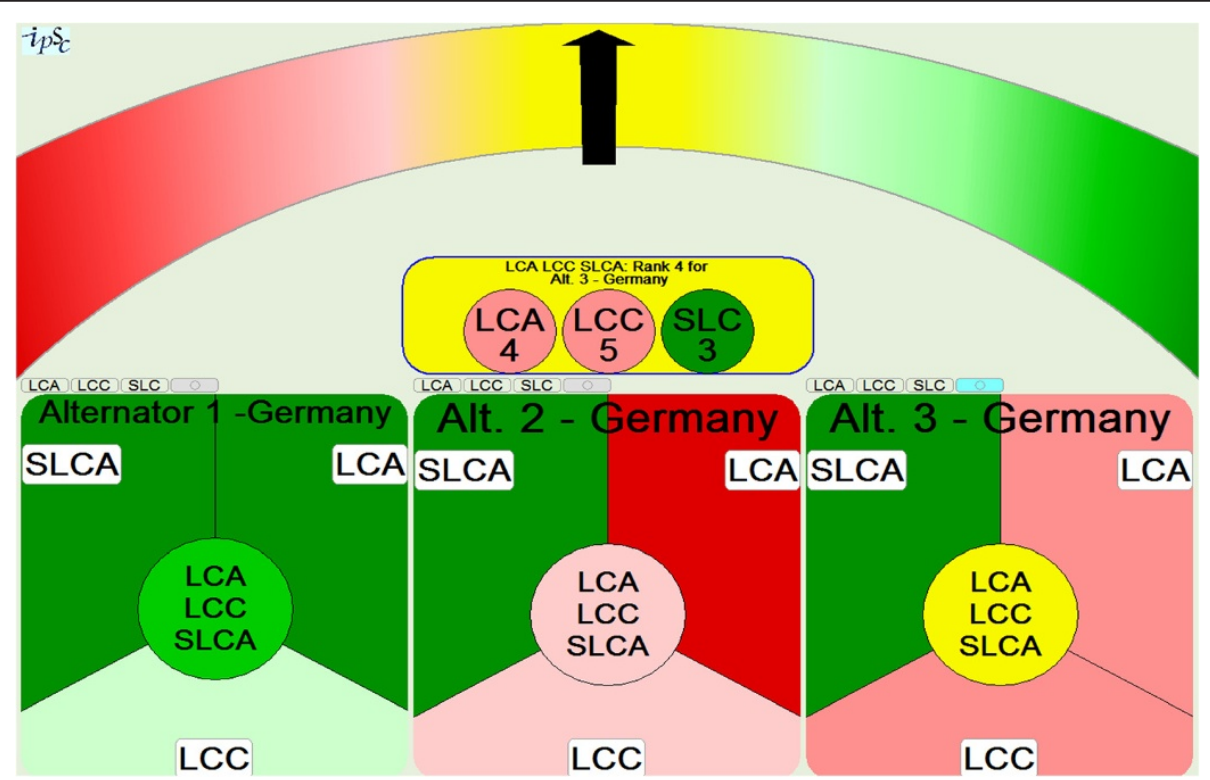

Figure 9 Life cycle sustainability assessment for the three different alternator designs remanufactured in Germany. 
design alternatives, however, the heaviest alternative, the conventional alternator, is the best option from an environmental and economic life cycle perspective. Our starting point for the analysis is that the three different design alternatives have the same performance (e.g. energy conversion efficiency) in the use phase. Therefore, the major share (i.e. for the electricity production) of the environmental and economic cost in the use phase is the same for all design alternatives. On the other side, the lightweight alternatives save some fuel in the use phase compared to the conventional heavier alternator due to the lighter weight. However, in a life cycle perspective, the saved energy in the use phase due to the lightweight materials is not enough to compensate for the increased life cycle environmental impact of the increased probability for changing this part (and replace with new spare parts) in the remanufacturing phase. For example, the iron cast housing in the conventional alternator needs to be replaced in $15 \%$ of the cores, while a lightweight aluminium housing needs to be replaced in $40 \%$ of the cores (cf. Table 1).

As discussed above, the weight-induced fuel use (cf. the costs in Figure 8) is relatively small in our study compared to the overall picture. Thus, the weight advantage during the use phase of the lightweight alternatives is not able to offset the higher impact of these alternators and parts (lightweight spare parts which are more frequently need to be replaced during the remanufacturing). In this regard, a curiosity occurs; if the alternators are used in Germany and shipped to India and Sierra Leone for remanufacturing and back again for further use in Germany, the economic and environmental costs for the oversea transport may be lower for the lightweight alternatives. However, in the present study, we have assumed that the transportation costs are the same for all design alternatives. A more precise estimate of the oversea shipping costs requires a more detailed logistic planning which we leave for further research.

The LCC results show that the costs for new spare parts are higher than a complete used alternator. Hence, an option to reduce the potential cost is to buy a used alternator. However, one of the main challenges in the remanufacturing industry is the difficulty of getting access to used alternators [56], so we have assumed that the future supply of used alternators will be limited. Also typically, the parts that need to be exchanged are the same for all used alternators. Thus, used alternators for serving spare parts are not considered as a valid option. This assumption also influences the LCA results.

The SLCA shows that exporting the working conditions standard from Germany to India and Sierra Leone could improve the situation for child labour, gender equity and poverty in these two countries. Child labour should not be tolerated in any considered remanufacturing scenario. This means a potential positive impact by the reduction of child labour in Sierra Leone and India, but without impact in Germany. While a ban of child labour for a new remanufacturing plant sounds reasonable, this may not be the case for existing child workers, where the alternatives for child performing labour has to be taken into account. A fruitful option to impede the child labour throughout the value chain can be to cooperate with fair trade non-governmental organisations. They often have experience from less-developed countries and can cooperate with local authorities and organisations to promote educational activities.

For the better balance between the genders, it is clear from Table 2 that further efforts have to be paid in Sierra Leone to reduce the difference between men and women. In this direction, the remanufacturing minifactory should be designed in a way such that women can also be employed. The poverty (here, measured on the ratio of the population living under US\$2 a day) is extremely high not only in Sierra Leone but also in India. To place the remanufacturing plant there and pay the workers a decent salary (the minimum wage in Sierra Leone is not enough for living) could make a small contribution to the right direction.

The emphasis on the life cycle is important also for the remanufacturer. The use phase and the upstream processes of the production of (new) spare parts contribute an essential part to the LCA and LCC results. This may also be vital to the SLCA, but here further data collection and research are still necessarily required.

Ideally, the same life cycle inventory (LCI) should be used for LCA, LCC and SLCA: 'The best solution would be the use of one identical LCI for all three components' (p. 90 in [27]). However, in this respect, it is worth to note that the inventory consists of the different types of data: for LCA typically, physical inputs and outputs; for LCC monetary flows and for SLCA, e.g., the social factors for the stakeholders. In addition, the life cycle phases of interest do not completely overlap for the three dimensions. For example, the remanufacturer perspective also includes the cost of warranties which belongs to the use phase. Therefore, some adjustment of the life cycle inventory is needed to fit the different life cycle techniques.

As the LCA and LCC results show, the most preferred environmental-friendly alternative also equipped the best cost efficiency, both from the remanufacturer and user perspectives. This case study shows that involved stakeholders can protect the environment and reduce the cost at the same time. Due to the predictive art of this study, limited data access and immature methodology, it has not been possible to clearly distinguish the three different designs alternatives regarding the SLCA. 
Even though the primary aim of the study is to compare the different alternator designs and remanufacturing sites, some findings for the LCA and LCC regarding the difference between new alternators and remanufactured alternators are possible to be drawn. By comparing the life cycle stages raw material extraction, material processing and manufacturing of the alternator production ( $c f$. upper left part in Figure 2) with the remanufacturing process (middle part of Figure 2), some findings are possible to reveal. We have shown in Figure 3 that the remanufacturing only need a fraction of the inputs (ADP elements and ADP fossil fuels) and only cause minimal emissions compared to the production of a new alternator. However, except in the ADP elements and RAD impact categories, the use phase is dominating under our assumption that the performance of the remanufactured alternator in the use phase is the same or better than a new alternator. This finding also holds for the LCC. Thus, our findings are in line with the study of Liu et al. [57] who found that the use of energy for remanufacturing of an engine motor is $10.22 \%$ compared to producing a new engine [57]. Therefore, the investigation of the performance of remanufactured alternators compared to new alternators in the use phase is extremely important. However, such an investigation requires more data $[58,59]$ on the performance and the driving distance of new and remanufactured alternators. We leave this question for further research.

With the increasing use of start/stop motor and hybrid vehicle, in addition to fully electrified drive train in modern automotives, the use of conventional alternators (in addition to the starters) are increasingly replaced by electro-motors. This calls for attention especially for remanufacturing companies specialised in remanufacturing alternators and starters. Where used automobiles are increasingly equipped without alternators and starters, changes both from the supply and the demand side are required. A shift towards remanufacturing of electromotors instead of alternators and starters could be an option.

As the energy efficiency of products (in the use phase) is improving, the reuse of materials is becoming relatively more important than the energy use and associated emissions. In the LCA, this means a shift from impact categories dominated by energy use to which categories that material use dominates. At the same time, when the energy use is decreasing (with its environmental and economic costs), the other dimension of sustainability, the social aspect which is measured with SLCA, is becoming more important for the life cycle sustainability impacts.

\section{Conclusions}

By applying LCA, LCC and SLCA, we have been able to quantify some indicators for the life cycle sustainability of the three different remanufactured alternators and remanufacturing localization options. While environmental LCA is widely used and the result for the environmental dimension of sustainability is relatively easily to interpret, the (environmental) LCC and SLCA still need further development.

The advanced development of the (environmental) LCC should focus on its relationship to sustainable development such as the links to wage: All monetary flows from one perspective (a cost) have a corresponding receiver (an income) from the other perspective. The further development of the SLCA should focus on case studies, where the complete life cycle and the suitable indicators are investigated. In this study, we have chosen to investigate child work, fair wages and gender equity out of more than 200 indicators available [60] for the remanufacturing phase only. Base line indicators suitable for comparison between product alternatives and (on a later stage) different SLCA studies should be agreed upon. This could bring better transparency to the results of SLCA studies. Important measures to improve the sustainability of the remanufacturing process seen from a life cycle perspective include the following: (a) to make sure the energy efficiency of the remanufactured part are like new or even better than the new part (this is important as the use phase dominates from an environmental and economic point of view), (b) to place the remanufacturing mini-plant in India or Sierra Leone while exporting German labour standards (this could improve the results for the social dimension of LCSA), and (c) to consider that lightweight parts are not necessarily better. In our case study, the conventional alternator is performing the best for the LCA and LCC. The conventional (heavy) parts are not replaced so often such that their life cycle environmental and economic performances are better. This implies that life cycle thinking is necessary in the decision process.

\section{Competing interest}

The authors declare that they have no competing interests.

\section{Authors' contributions}

EMS reviewed the literature on LCSA and remanufacturing and had the leading role in performing the LCSA. He wrote the paper and prepared the figures and tables. MT had the leading role in conducting the SLCA. MF defined the case object (alternator) and directed the research from the start to the end. MT and MF provided important advices throughout the study and helped in editing the manuscript. All authors read and approved the final manuscript.

\section{Authors' information}

EMS led the research project 'Methodological sustainability assessment of machine components in the development process' which was part of a larger university-wide multidisciplinary research project 'Sustainable value creation exemplified by a mini-factory for remanufacturing' at the Technische Universitaet Berlin (TU-Berlin). He is now involved in the Collaborative Research Centre (CRC) 1026 'Sustainable Manufacturing Shaping Global Value Creation.' He holds a Master of Science and Ph.D. in Industrial Economics and Technology Management from the Norwegian 
University of Science and Technology (NTNU) in Trondheim, Norway. EMS has experiences from life cycle assessment of automotive products, transport and food products. He wrote several papers for international scientific journals and conferences. He is also a reviewer for a scientific research organisation and international journals such as Environmental Science \& Technology.

MT is an expert on LCSA and SLCA. She was working as a post-doctoral scientific assistant in the Chair of Sustainable Engineering of TU-Berlin. She is an environmental engineer and holds a Ph.D. of 'Environmental Applied Physics' from the University of Palermo, Italy. She was working in the applications of LCA on building sector and strategic environmental assessment to the urban transportation systems. She was also a reviewer of a European Ph.D thesis 'Sustainability assessment within the residential building sector: a practical life cycle method applied in a developed and a developing country'. She joined the working group of UNEP/SETAC Life Cycle Initiative for developing the first guideline of LCSA. She currently involves in a UNEP Life Cycle Initiative of developing methodological sheets of Social Life Cycle Assessment guidelines. She wrote several papers for national and international scientific magazines and congresses, and she reviewed papers for international scientific magazine such as Sustainability Journal.

MF is currently Chair of Sustainable Engineering and Vice-Director of the Department of Environmental Technology at TU-Berlin. In addition, he is Advisory Professor for Sustainability Assessment at Aalto University Helsinki. He spent several years in industry including Mercedes-Benz Car Group of Daimler AG, Stuttgart, Germany as manager for Life Cycle Assessment and Life Cycle Engineering at the Design-for-Environment Department. Furthermore, he was leading vehicle projects with alternative powertrains (fuel cell, hybrid, etc.). He is a member of the Chairman's Advisory Committee and CHAIR of the Portfolio Task Force in TC207 for the ISO 14000 series of standards, and chairman of the ISO TC207/SC5 Life Cycle Assessment. He serves as a member of the International Life Cycle Board of the UNEP/SETAC Life Cycle Initiative and leader of their carbon footprint project. Moreover, he is a member of the Steering Committee of the Greenhouse Gas Protocol Product/Supply Chain Initiative of WBCSD/WRI and was appointed as member of the governing body of the 'Blue Angel' in Germany. MF is involved in several projects of UNEP/SETAC life cycle initiative e.g., guidelines of SLCA and guidelines of LCSA; he is also the vice speaker and a project leader of the CRC 1026 Sustainable Manufacturing Shaping Global Value Creation. MF published more than 80 papers and serves on several editorial boards (International Journal of Life Cycle Assessment, and ReSource, Waste Management \& Research).

\section{Acknowledgements}

We acknowledge Sara J. Ridley from Caterpillar Reman Service who gave us the idea to cooperate with fair trade non-governmental organisations to impede child labour on the conference dinner at the International Conference on Remanufacturing, Glasgow 27-29 July 2011.

We thank Barbra Ruben and Jan Fiebig for help collecting data and Ya-Ju Chang for help on English proofreading. We thank Kai Lindow, Robert Woll and Rainer Stark at Department of Industrial Information Technology, Technische Universitaet Berlin for their helpful cooperation. The position of EMS is supported by the German Research Foundation DFG (Fi 1622/1-1 and SFB 1026/1 2012). The article processing charge is kindly waived by the organiser of the International Conference of Remanufacturing (ICoR), Dr Winifred ljomah and Dr James Windmill in cooperation with BioMed Central.

Received: 25 May 2012 Accepted: 8 November 2012 Published: 13 December 2012

\section{References}

1. Kim, H-J, Skerlos, S, Severengiz, S, Seliger, G: Characteristics of the automotive remanufacturing enterprise with an economic and environmental evaluation of alternator products. INT. J. Sustain. Man. 1, 437-449 (2009)

2. Meyer, R: Generatoren und Starter [Energieerzeugung und Bordnetz Physikalische Grundlagen, Geräteausführungen für PKW und Nkw, Qualitätsmanagement, Werkstatt-Technik]. Bosch, Stuttgart (2002)
3. Lindahl, $M$, Sundin, E, Östlin, J: Environmental issues within the remanufacturing industry. In: 13th CIRP International Conference on Life Cycle Engineering, pp. 447-452. K.U. Leuven, Leuven (May 31-June 2 2006)

4. Boustani, A, Sahni, S, Graves, SC, Gutowski, TG: Appliance remanufacturing and life cycle energy and economic savings. In: Sustainable Systems and Technology (ISSST), pp. 1-6. 2010 IEEE International Symposium, Arlington, VA (17-19 May 2010)

5. Mayer, HW, Pester, W: Die Aufarbeitung von Kfz-Komponenten birgt Potenzial für Kunden und Umwelt. VDI Nachrichten 64, 24 (2010)

6. Warsen, J, Laumer, M, Momberg, W: Comparative life cycle assessment of remanufacturing and new manufacturing of a manual transmission. In: Hesselbach, J, Herrmann, C (eds.) Glocalized Solutions for Sustainability in Manufacturing, pp. 67-72. Springer Berlin, Heidelberg (2011)

7. Sundin, E, Lee, HM: In what way is remanufacturing good for the environment? In: Design for Innovative Value Towards a Sustainable Society: Proceedings of EcoDesign 2011: 7th International Symposium on Environmentally Conscious Design and Inverse Manufacturing, pp. 552-557. Springer, New York (2012)

8. Schau, EM, Traverso, M, Lehmann, A, Finkbeiner, M: Life cycle costing in sustainability assessment - a case study of remanufactured alternators. Sustainability 3, 2268-2288 (2011)

9. $\mathrm{Ke}, \mathrm{Q}, \mathrm{Zhang}, \mathrm{H}-\mathrm{C}, \mathrm{Liu}, \mathrm{G}, \mathrm{Li}, \mathrm{B}$ : Remanufacturing engineering literature overview and future research needs. In: Hesselbach, J, Herrmann, C (eds.) Glocalized Solutions for Sustainability in Manufacturing, pp. 437-442. Springer, Berlin (2011)

10. Brundtland, GH: World Commission on Environment and Development: Our Common Future. Oxford University Press, Oxford (1987)

11. ISO 14040: Environmental management - life cycle assessment - principles and framework (ISO 14040:2006), 2nd edn. ISO, Geneva (2006)

12. ISO 14044: Environmental management - life cycle assessment requirements and guidelines (ISO 14044:2006). ISO, Geneva (2006)

13. Guinée, JB, Gorrée, M, Heijungs, R, Huppes, G, Kleijn, R, de Koning, A, van Oers, L, Sleeswijk, AW. Suh, S, de Haes, HA: U, de Bruijn, H, van Duin, R, Huijbregts, MAJ: Handbook on Life Cycle Assessment - Operational Guide to the ISO Standards. Kluwer, Dordrecht (2002)

14. Klöpffer, W, Grahl, B: Ökobilanz (LCA): Ein Leitfaden für Ausbildung und Beruf. Wiley-VCH, Weinheim (2009)

15. Lichtenvort, K, Rebitzer, G, Huppes, G, Ciroth, A, Seuring, S, Schmidt, W-P, Günther, E, Hoppe, H, Swarr, T, Hunkeler, D: Introduction - history of life cycle costing, its categorization, and its basic framework. In: Hunkeler, D, Lichtenvort, K, Rebitzer, G (eds.) Environmental Life Cycle Costing, pp. 1-6. CRC Press \& SETAC, Boca Raton (2008)

16. Hunkeler, D, Lichtenvort, K, Rebitzer, G: Environmental Life Cycle Costing CRC Press, Boca Raton (2008)

17. Rebitzer, G, Nakamura, S: Environmental life cycle costing. In: Hunkeler, D, Lichtenvort, K, Rebitzer, G (eds.) Environmental Life Cycle Costing, pp. 35-57. CRC Press, Boca Raton (2008)

18. Klöpffer, W: Outlook - role of environmental life cycle costing in sustainability assessment. In: Environmental Life Cycle Costing. CRC Press, Boca Raton (2008)

19. Benoit, C, Mazijn, B: Guidelines for Social Life Cycle Assessment of Products. United Nations Environment Programme, Paris (2009)

20. Swarr, TE, Hunkeler, D, Klopffer, W, Pesonen, H-L, Ciroth, A, Brent, AC, Pagan, R: Environmental Life-Cycle Costing: A SETAC Code of Practice. SETAC Press, Pensacola (2011)

21. Valdivia, S, Sonnemann, G, Hildenbrand, J: Towards a Life Cycle Sustainability Assessment - Making informed choices on products. UNEP/ SETAC Life Cycle Initiative, Paris (2011)

22. Finkbeiner, M, Schau, EM, Lehmann, A, Traverso, M: Towards life cycle sustainability assessment. Sustainability 2, 3309-3322 (2010)

23. Klöpffer, W, Renner, I: Life-cycle based sustainability assessment of products. In: Schaltegger, S, Bennett, M, Burritt, RL, Jasch, C (eds.) Environmental Management Accounting for Cleaner Production. In series Tukker A (ed): Eco-Efficiency in Industry and Science vol. 24, pp. 91-102. Springer Netherlands, Dordrecht (2009)

24. Klöpffer, W: Life-cycle based methods for sustainable product development. Int. J. Life Cycle Assess. 8, 157-159 (2003)

25. Finkbeiner, M, Reimann, K, Ackermann, R: Life cycle sustainability assessment 
(LCSA) for products and processes. In: SETAC Europe 18th Annual Meeting; 25-29 May 2008. Warsaw, Poland (2008)

26. Lozano, R: Envisioning sustainability three-dimensionally. J. Clean. Prod 16, 1838-1846 (2008)

27. Kloepffer, W: Life cycle sustainability assessment of products (with comments by Helias A. Udo de Haes, p. 95). Int. J. Life Cycle Assess 13 89-95 (2008)

28. Hischier, R, Baitz, M, Bretz, R, Frischknecht, R, Jungbluth, N, Marheineke, T, McKeown, P, Oele, M, Osset, P, Renner, I, Skone, T, Wessman, H, de Beaufort, ASH: Guidelines for consistent reporting of exchanges from/to nature within life cycle inventories (LCI). Int. J. Life Cycle Assess. 6, 192-198 (2001)

29. Postawa, AB: Personal communication about alternator parts and their replacement probability. Department for Machine Tools and Factory Management. Technische Universitaet Berlin, Germany (2010)

30. Lindow, K: Personal communication about materials, weights and replacement probabilities in alternative design of alternators. Chair Industrial Information Technology, Department of Machine Tools and Factory Management. Technische Universität Berlin, Germany (2010)

31. PE, LBP: GaBi 4 - Software-System and Databases for Life Cycle Engineering., Stuttgart, Echterdingen (2009). ver. 4.4.137

32. CML: CML-IA Characterisation Factor; version 3.6. Leiden University, Leiden (2009). http://cml.leiden.edu/software/data-cmlia.html. Accessed 17 Nov 2010

33. Norris, CB, Aulisio, D, Norris, GA: Working with the Social Hotspots Database - methodology and findings from 7 Social Scoping Assessments. In: Dornfeld, D.A., Linke, B.S. (eds.) Leveraging Technology for a Sustainable World, pp. 581-586. Springer, Berlin (2012)

34. Benoit, C, Norris, G: Social Hotspots Database. http://www.socialhotspot.org/. Accessed 10 Jan 2011

35. Traverso, M, Finkbeiner, $M$, Jørgensen, A, Schneider, L: Life cycle sustainability dashboard. J. Ind. Ecol 16, 680-688 (2012)

36. Sundin, E, Björkman, M, Jacobsson, N: Analysis of service selling and design for remanufacturing. In: Proceedings of the 2000 IEEE International Symposium on Electronics and the Environment, pp. 272-277. ISEE - 2000, San Francisco, CA (8-10 May 2000)

37. Benoit, C: Development of a screening tool for social LCA: the Social Hot Spots Database part 1. In: Life Cycle Assessment IX 'toward the global life cycle economy'. ACLCA, Boston (29 Sept-2 Oct 2009)

38. Benoit, C, Norris, G, Valdivia, S, Ciroth, A, Moberg, A, Bos, U, Prakash, S, Ugaya, C, Beck, T: The guidelines for social life cycle assessment of products: just in time! Int. J. Life Cycle Assess. 15, 156-163 (2010)

39. Statistics Sierra Leone: UNICEF-Sierra Leone: Sierra Leone - Multiple Indicator Cluster Survey 2005. Statistics Sierra Leone and UNICEF-Sierra Leone. Freetown, Sierra Leone (2007)

40. UNICEF: Childinfo: statistics by area/child protection - percentage of children aged 5-14 engaged in child labour http://www.childinfo.org/ labour_countrydata.php. Accessed 30 March 2011

41. International Labour Organization: Minimum Age Convention, (No. 138). ILO Geneva (1973). http://www.lo.org/ilolex/cgi-lex/convde.pl?C138. Accessed 30 March 2011

42. World Bank: World Development Indicators \& Global Development Finance., (2011). http://databank.worldbank.org/. Accessed 20 Feb 2012

43. The World Bank: Poverty Headcount Ratio at a Day (PPP) (\% of population) http://data.worldbank.org/indicator/SI.POV.2DAY (2011). Accessed 29 Jan 2011

44. ILC: International Comparisons of Hourly Compensation Costs in Manufacturing. (2008). http://www.bls.gov/news.release/pdf/ichcc.pdf. Accessed 17 Dec 2010

45. ILO: Wages in Manufacturing (Table five B). (2010). http://laborsta.lo.org/. Accessed 17 Dec 2010

46. Sincavage, JR, Haub, C, Sharma, O: Labor costs in India's organized manufacturing sector. Mon. Labor Rev. 133, 3-22 (2010)

47. Paycheck.in: Minimum Wages India - Current Minimum Wages Rate India. (2011). http://www.paycheck.in/main/officialminimumwages. Accessed 22 March 2011

48. Paycheck.in: Minimum Wages in Maharashtra. (2011). http://www.paycheck. in/main/officialminimumwages. Accessed 22 March 2011

49. 2008 Human Rights Report: Sierra Leone. http://www.state.gov/g/drl/rls/ hrrpt/2008/af/119023.htm. Accessed 16 Dec 2010

50. Statistics Sierra Leone: 2008 Annual Economic Survey. Statistics Sierra Leone, Economic Statistics Division, Freetown, Sierra Leone (2009)
51. Traverso, M, Finkbeiner, M: Life Cycle Sustainability Dashboard. In: Proceedings of the 4th International Conference on Life Cycle Management, pp. 6-9. Cape Town, South Africa (September 2009)

52. Bradfield, M: Improving alternator efficiency measurably reduces fuel costs, In: Improving Alternator Efficiency Measurably Reduces Fuel Costs. Remy Inc, Pendleton (2008)

53. Ajayi, OA: Application of automotive alternators in small wind turbines. TU-Delft, Delft (2012)

54. Kuppers, S, Henneberger, G: Numerical procedures for the calculation and design of automotive alternators. IEEE T. Magn. 33, 2022-2025 (1997)

55. Ijomah, WL, McMahon, CA, Hammond, GP, Newman, ST: Development of design for remanufacturing guidelines to support sustainable manufacturing. Robot. Cim-Int. Manuf. 23, 712-719 (2007)

56. Östlin, J, Sundin, E, Björkman, M: Product life-cycle implications for remanufacturing strategies. J. Clean. Prod. 17, 999-1009 (2009)

57. Liu, S-c, Shi, P-j, Xu, B-s, Xing, Z, Xie, J-j: Benefit analysis and contribution prediction of engine remanufacturing to cycle economy. J. Cent. S. Univ. Technol. 12, 25-29 (2005)

58. Lund, RT: Comment on "Remanufacturing and Energy Savings". Environ. Sci. Technol. 45, 7603-7603 (2011)

59. Gutowski, TG, Sahni, S, Boustani, A, Graves, SC: Remanufacturing and energy savings. Environ. Sci. Technol. 45, 4540-4547 (2011)

60. Hunkeler, D: Societal LCA methodology and case study. Int. J. Life Cycle Assess 11, 371-382 (2006)

doi:10.1186/2210-4690-2-5

Cite this article as: Schau et al:: Life cycle approach to sustainability assessment: a case study of remanufactured alternators. Journal of Remanufacturing 2012 2:5.

\section{Submit your manuscript to a SpringerOpen ${ }^{\odot}$ journal and benefit from:}

- Convenient online submission

Rigorous peer review

- Immediate publication on acceptance

- Open access: articles freely available online

- High visibility within the field

- Retaining the copyright to your article

Submit your next manuscript at $\gg$ springeropen.com 